\title{
Possible phase transformation toughening of thermoset polymers by poly(butylene terephthalate)
}

\author{
JUNKYUNG KIM, R. E. ROBERTSON* \\ Macromolecular Science and Engineering Center, and Department of Materials Science and \\ Engineering, The University of Michigan, Ann Arbor, M1 48109, USA
}

\begin{abstract}
Mechanisms were explored by which particles of poly(butylene terephthalate) (PBT) are able to toughen a brittle epoxy. The epoxy studied was an aromatic amine-cured diglycidyl ether of bisphenol-A, which was toughened at about twice the rate with particles of poly (butylene terephthalate) as with particles of nylon 6, poly (vinylidene fluoride), or CTBN rubber. Many of the mechanisms of toughening are visible on the fracture surface of the PBT-epoxy blend, but a mechanism suggested to account for perhaps half of the increased toughness with PBT, phase transformation toughening, is not. The two types of experiment performed to detect phase transformation toughening were: (1) measurements of the rubber cavitation zone in PBT-CTBN rubber-epoxy ternary blends, which would detect an expansion of the PBT particles during fracture if it occurred, and (2) measurements of the fracture energy in PBT-epoxy blends in which the various mechanisms of toughening were selectively suppressed. Both types of experiment indicated the occurrence of phase transformation toughening in these PBT-epoxy blends.
\end{abstract}

\section{Introduction}

One of the most important properties for materials intended for load-bearing applications is toughness, the resistance to crack propagation. Brittle network or thermoset polymers are often used as the matrix in structural composites because of their high stiffness and high strength, but their low toughness, especially in the presence of sharp notches, detracts from this usage. Hence, an improvement in the toughness of brittle network or thermoset polymers is greatly desired. Toughness of thermoset resins has often been attained by incorporating rubber particles [1-7]. The improvement in toughness of rubber-toughened thermosets can be remarkable, but not all thermosets are significantly toughened by rubber. Epoxies with low cross-link densities can have their toughness greatly increased by the inclusion of rubber, but highly cross-linked epoxies usually cannot. Moreover, the high stiffness and strength of thermoset resins are inevitably reduced by adding an elastomer of low stiffness and strength. In addition, the elastomeric phase increases the melt viscosity of the mixture, thus reducing processability. So other toughening methods for brittle polymers must be sought.

We recently reported the toughening by particulate inclusions of three crystalline polymers of a highly cross-linked epoxy that cannot be toughened significantly by inclusion of rubber [8]. The crystalline poly- mers studied were poly(butylene terepthalate) (PBT), nylon 6, and poly(vinylidene fluoride) (PVDF). There was no loss of either Young's modulus or yield strength of the epoxy with the inclusion of either nylon 6 or PBT and less loss of these with the inclusion of PVDF than with the inclusion of rubber. As is shown in Fig. 1, nylon 6 and PVDF were found to toughen the epoxy about as well as did an equivalent amount of CTBN rubber. But PBT was found to toughen the epoxy about twice as well as did the rubber and other polymers. The enhancement of toughness seems to have arisen from a combination of mechanisms. The exceptional toughness of PBT-epoxy blends was suggested to have arisen from "phase transformationtoughening".

Phase transformation toughening has exhibited a dramatic toughening of a brittle matrix in zirconiacontaining ceramics [9-14]. The metastable tetragonal phase of zirconia, incorporated into a brittle ceramic, transforms under the influence of the stress field ahead of a crack tip to the stable monoclinic phase. Because the monoclinic is less dense than the tetragonal phase, a compressive stress results that is superimposed on the tensile stress field ahead of the crack tip. This slows or stops the growing crack and has the effect of increasing the critical fracture energy.

The purpose of the present work has been to investigate the hypothesis that the PBT-epoxy blends

* Author to whom all correspondence should be addressed. 


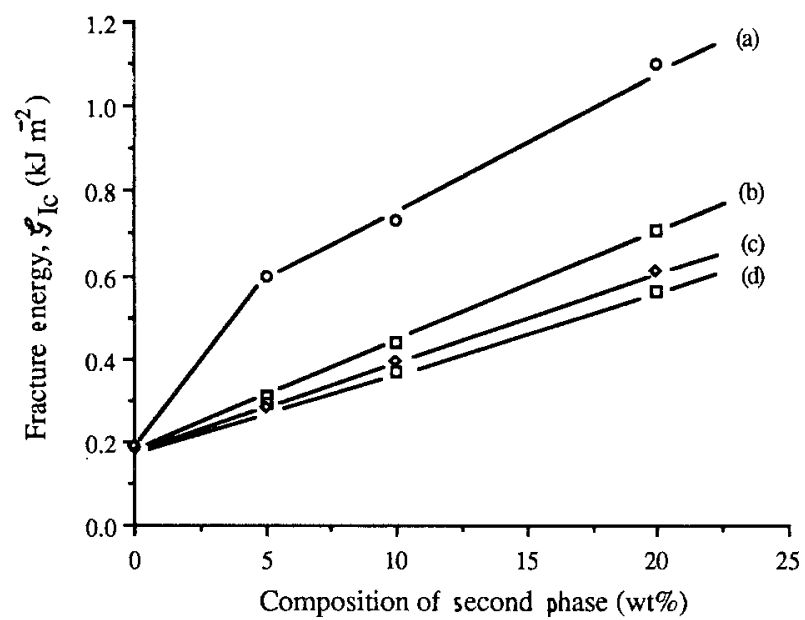

Figure 1 Fracture energy for initiation for (a) PBT, (b) nylon 6, (c) CTBN, and (d) PVDF [8]

gained toughness from phase transformation toughening. Direct evidence that the PBT is transformed during fracture has not been found. The $\beta$-phase is unstable, and in the absence of an applied stress, it reverts back to the $\alpha$-form. Thus, an X-ray study of the PBT at the fracture surface shows only the $\alpha$-form. An attempt was made also to examine the PBT structure under stress at the tip of a crack using Raman scattering. The interaction between the highly focused, intense laser beam of the Raman instrument with the coloured materials of the specimen led to a rapid pyrolysis of the specimen, however. Thus, the evidence available is of an indirect nature and is of two types. The first is a test of the expansion of the PBT particles during fracture. If the PBT did transform, the stress field ahead of the crack tip would be affected by the volume expansion of the PBT accompanying the transformation. One stress-field sensitive phenomenon is the cavitation of the particulate rubber in rubber-epoxy blends. Thus, as a test for the phase transformation of PBT, a series of experiments was performed in which the effect of PBT on rubber cavitation in PBT-rubber-epoxy blends was studied. The second is a study of the fracture energy of PBT-epoxy blends when various energy-absorbing mechanisms are suppressed.

\section{Experimental procedure}

\subsection{Materials}

The polymers used in this study were an epoxy, poly(butylene terephthalate), and CTBN rubber. The epoxy was diglycidyl ether of bisphenol A, Epon 828, that was cured with Curing Agent $Z$, a mixture of aromatic amines with the main component being $4,4^{\prime}$ methylenedianiline. The optimum concentration of Curing Agent $Z, 20$ p.h.r., was used, and the epoxy-curing agent mixture was cured at $80^{\circ} \mathrm{C}$ for $2 \mathrm{~h}$ and post-cured at $150^{\circ} \mathrm{C}$ for another $2 \mathrm{~h}$. The glass transition temperature of the cured epoxy was $156^{\circ} \mathrm{C}$.

The poly(butylene terephthalate) (PBT) used had an inherent viscosity in phenol at $40^{\circ} \mathrm{C}$ of 0.71 . To facilitate incorporation into the epoxy blend, the PBT was made into particulate form by discussion in phenol and precipitation in methanol. After further washing in methanol and drying, the PBT was milled and sieved to obtain a uniform particle size. The dilute solution viscocity of the powder was the same as that of the original bead. The PBT powder was dried under vacuum before mixing with epoxy.

The PBT was incorporated into the epoxy matrix by one of three methods. In Process $1,15 \mu$ m diameter PBT particles, curing agent, and the epoxy were mixed together at room temperature. After degassing, this mixture was cured at $80^{\circ} \mathrm{C}$ and post-cured at $150^{\circ} \mathrm{C}$. In Process 2, $15 \mu \mathrm{m}$ diameter PBT particles were mixed with the epoxy at room temperature without curing agent. This mixture was heated without stirring at a rate of about $10^{\circ} \mathrm{C} \mathrm{min}^{-1}$ to $220^{\circ} \mathrm{C}$ and then immediately cooled to room temperature. The curing agent was added, and this mixture was cured and postcured as above. In process $3,1 / 8$ in $(\sim 3 \mathrm{~mm})$ diameter PBT pellets were mixed with the epoxy without curing agent at room temperature, and this mixture was heated at a rate of about $10^{\circ} \mathrm{C} \mathrm{min}^{-1}$ to $230^{\circ} \mathrm{C}$. After about $10 \mathrm{~min}$ at this temperature, with stirring, the PBT had dissolved in the epoxy. The mixture was cooled to room temperature, where the curing agent was added, and the mixture was cured at $80^{\circ} \mathrm{C}$ and post-cured at $150^{\circ} \mathrm{C}$, as in Processes 1 and 2 .

The rubber used was Hycar CTBN $1300 \times 13$. It is a liquid copolymer of butadiene and acrylonitrile with carboxyl end groups. According to the manufacturer's literature, the carboxyl content is $2.40 \%$, the acrylonitrile content is $27.0 \%$, and the molecular weight is 3500 . For mixtures of the rubber in the epoxy matrix, the rubber was stirred with epoxy for $1 \mathrm{~h}$ at $120^{\circ} \mathrm{C}$ to dissolve it. After dissolution, the mixture was cooled to room temperature, and the curing agent was added. The mixture was cured and post-cured as above. Precipitation of the rubber phase occurred during the curing process, and the diameter of the resulting rubber particles was approximately $0.7 \mu \mathrm{m}$.

For mixtures of PBT and CTBN rubber in the epoxy matrix, a process similar to Process 1 was used. After the rubber had been dissolved in the epoxy at $120^{\circ} \mathrm{C}$ and cooled to room temperature, $15 \mu \mathrm{m}$ diameter PBT particles and curing agent were added. After degassing, this mixture was cured at $80^{\circ} \mathrm{C}$ and post-cured at $150^{\circ} \mathrm{C}$, as above.

\subsection{Fracture tests}

The double-torsion test (DT test), which was first described by Kies and Clark [15], was used for measuring toughness. This method was initially designed for brittle ceramic materials [16-19], but has since been used widely for brittle polymers such as epoxies [20-25]. The double-torsion specimen, having the shape roughly of a pair of pants, can be considered to be a pair of elastic torsion bars, each having a rectangular cross-section. A diagram of the DT specimen and loading configuration is shown in Fig. 2. For small deflections, the fracture toughness, $K_{\mathrm{Ic}}$, is given by

$$
K_{\mathrm{lc}}=P_{\mathrm{crit}} W_{\mathrm{n}}\left[3(1+v) / W t^{3} t_{\mathrm{n}}\right]^{1 / 2}
$$




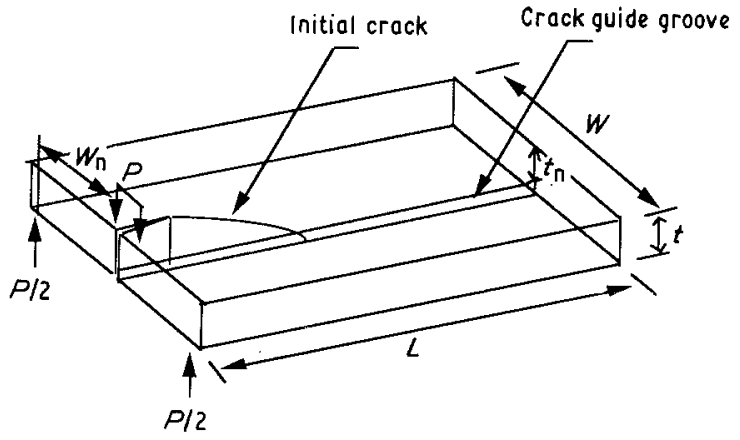

Figure 2 Double torsion specimen geometry [8].

where $P_{\text {crit }}$ is the load at which crack growth initiation or arrest occurs, $W_{\mathrm{n}}$ is the moment arm of each torsion bar, $v$ is Poisson's ratio, $W$ is the specimen width, $t$ the thickness, and $t_{\mathrm{n}}$ is the specimen thickness where fracture is occurring. As can be seen from the equation, the fracture toughness is a function only of the applied load, the specimen dimensions, and Poisson's ratio and is independent of crack length. The latter feature makes the double torsion test extremely useful for sub-critical crack growth studies.

The fracture energy, $\mathscr{G}_{\mathrm{Ie}}$, is related to the fracture toughness by

$$
K_{\mathrm{Ic}}=\left(E \mathscr{G}_{\mathrm{Ic}}\right)^{1 / 2}
$$

where $E$ is Young's modulus.

The specimens used had a rectangular shape with the dimensions of $100 \mathrm{~mm}$ long, $30 \mathrm{~mm}$ wide, and $6 \mathrm{~mm}$ thick. A sharp crack was inserted at one end, and a shallow centre groove was cut along one face of the specimen. The sharp crack prevents the formation of a plastic zone in the vicinity of the crack tip and was inserted by tapping with a hammer on a razor blade held against the bottom of a saw cut. The initial crack lengths were made longer than 0.55 times the specimen width to avoid end effects [17]. The centre groove guides the propagating crack and was made with a table saw. The width of the groove was less than $0.5 \mathrm{~mm}$, and the depth was nearly one-half the specimen thickness. The load was applied with a screwdriven Instron machine at $0.04 \mathrm{~mm} \mathrm{~s}^{-1}$ crosshead speed. The load against time was recorded with a strip chart recorder.

\subsection{Fractography}

Scanning electron microscopy (SEM) was used to study and record the fractured surfaces of the pure and modified epoxies. The fractured sample surfaces were coated with a thin layer $(10-30 \mathrm{~nm})$ of goldpalladium. This coating was carried out by placing the specimen in a high-vacuum evaporator and vaporizing the metal held in a heated tungsten basket.

Polarized transmission optical microscopy was used to investigate the structure and deformation below the fracture surface. Under polarized light, the plastic deformation zone can be detected by the induced birefringence. Thin sections were used for the microscopy. These were obtained by metallographic thinning techniques [26] and were typically taken

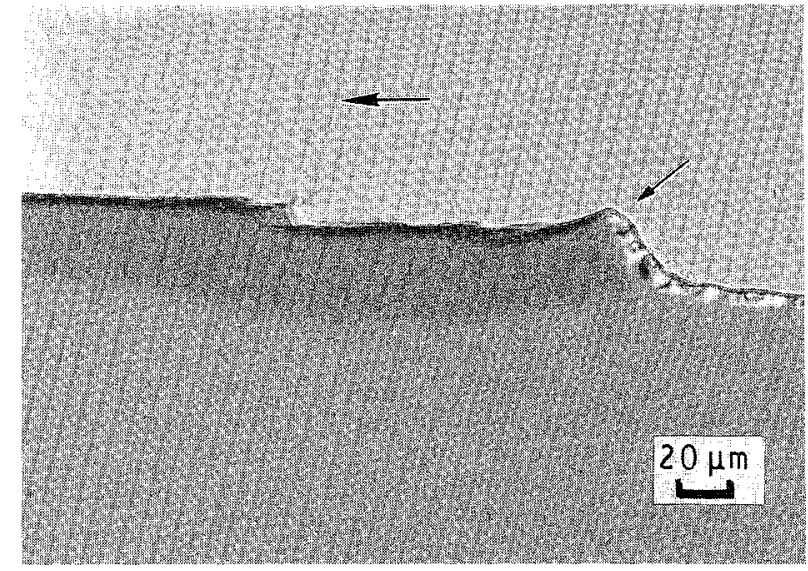

Figure 3 Optical micrograph of a thin section perpendicular to the fracture surface of $10 \mathrm{wt} \% \mathrm{CTBN}$ rubber-epoxy blend. The large and small arrows indicate the crack propagation direction and blunt notch root, respectively.

from the mid-region of a three-point bending specimen. The section plane was parallel to the crack propagation direction and normal to the fracture surface. The specimens for the three-point bending were $30 \mathrm{~mm}$ by $10 \mathrm{~mm}$ and $6 \mathrm{~mm}$ thick, with a $3 \mathrm{~mm}$ deep notch in one side that was inserted with a $0.2 \mathrm{~mm}$ thick saw blade.

\section{Results}

\subsection{Cavitation zone size}

When fracture is initiated at the root of a blunt notch in a CTBN rubber-reinforced epoxy specimen, the rubber particles around the fracture plane cavitate [4]. This can be seen in the thin section shown in Fig. 3. This section was obtained from a specimen that before being fractured in three-point bending had been $30 \mathrm{~mm}$ by $10 \mathrm{~mm}$ and $6 \mathrm{~mm}$ thick, with a $3 \mathrm{~mm}$ deep notch in one side that was inserted with a $0.2 \mathrm{~mm}$ thick saw blade. The thin section shown in Fig. 3 was cut with its plane parallel to the direction of crack propagation and perpendicular to the fracture surface. The point of initiation at the root of the saw-cut is indicated by the smaller arrow; the larger arrow indicates the direction of crack propagation. Cavitation is indicated by the darker band just beneath the fracture surface, which results from the scattering of transmitted light by the cavitated particles in this optical micrograph. The fully formed band has a thickness of about $25 \mu \mathrm{m}$. The cavitation is induced by the triaxial tensile stress that precedes the crack tip [5].

When both CTBN rubber and PBT are added to the epoxy resin, the cavitation zone size is found to decrease from that of CTBN rubber-epoxy blends without PBT. A plot of the cavitation zone size in these specimens relative to that of the $10 \mathrm{wt} \% \mathrm{CTBN}$ rubber-epoxy blend without PBT is shown in Fig. 4. The decrease in cavitation zone size is essentially proportional to the amount of PBT, falling to zero around $17 \mathrm{wt} \%$. By contrast with the decrease in cavitation zone size upon the addition of PBT, the addition of nylon 6 or poly(vinylidene fluoride) (PVDF) caused no such change. 


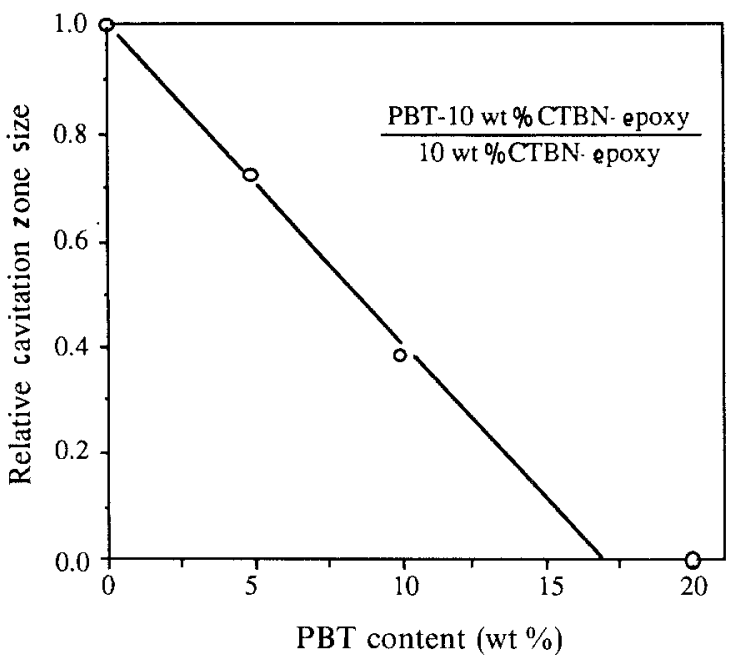

Figure 4 Cavitation zone size relative to that for $10 \mathrm{wt} \%$ CTBN rubber-epoxy without PBT versus PBT content.

\subsection{Selective suppression of toughening mechanisms}

The toughness induced in brittle polymers like epoxies by the presence of particles of a different polymer arises in all cases, including with PBT, from a combinations of mechanisms. In the present experiments, the relative importance of the different mechanisms of toughening in PBT-epoxy blends was changed by preparing the blend in different ways. Three different ways were employed, denoted Processes 1, 2, and 3, as described in Section 2.1.

A comparison of the fracture energy versus PBT content for the PBT-epoxy blends made by the three different processes is shown in Fig. 5. For PBT-epoxy blends made by Process 1 , the fracture energy of the blend increased rapidly up to $5 \mathrm{wt} \% \mathrm{PBT}$, and then, at higher composition, the fracture energy increased almost linearly at a lower rate. In Process 2, the fracture energy increased up to $5 \mathrm{wt} \%$ PBT, but above $5 \mathrm{wt} \% \mathrm{PBT}$, the fracture energy remained relatively constant at around $750 \mathrm{~J} \mathrm{~m}^{-2}$. In Process 3 , the fracture energy enhancement was negligible over the whole composition range tested and was almost the same as that of the unfilled epoxy.

The toughening mechanisms are best revealed by examining the fracture surfaces. SEM micrographs of fracture surfaces of PBT-epoxy blends made by different processing conditions are shown in Figs 6-11.

The general fracture surface morphology occurring with PBT-epoxy blends made by Process 1 is shown in Fig. 6. As can be seen, there occurred behind nearly every PBT particle, irrespective of particle size, a taillike crack bifurcation line with welts of notable thickness. Another feature seen on the fracture surface that can be indicative of the mechanisms of fracture and toughness is the basic longitudinal texture (BLT). The BLT is a linear pattern of just barely discernable ridges and grooves that are locally parallel with the direction of crack propagation. The BLT is visible at higher magnifications, as in Fig. 7. The texture of the BLT is found to rotate around the PBT particles for all PBT compositions. A further characteristic of fracture of the blends made by Process 1 is the ductile

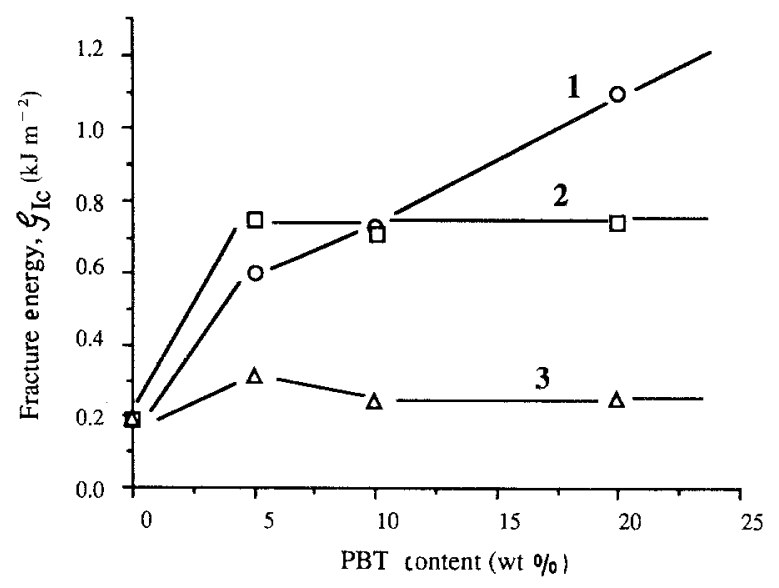

Figure 5 Effect of three preparation methods (Processes 1, 2, and 3) on the fracture energy of PBT-epoxy blends [45].

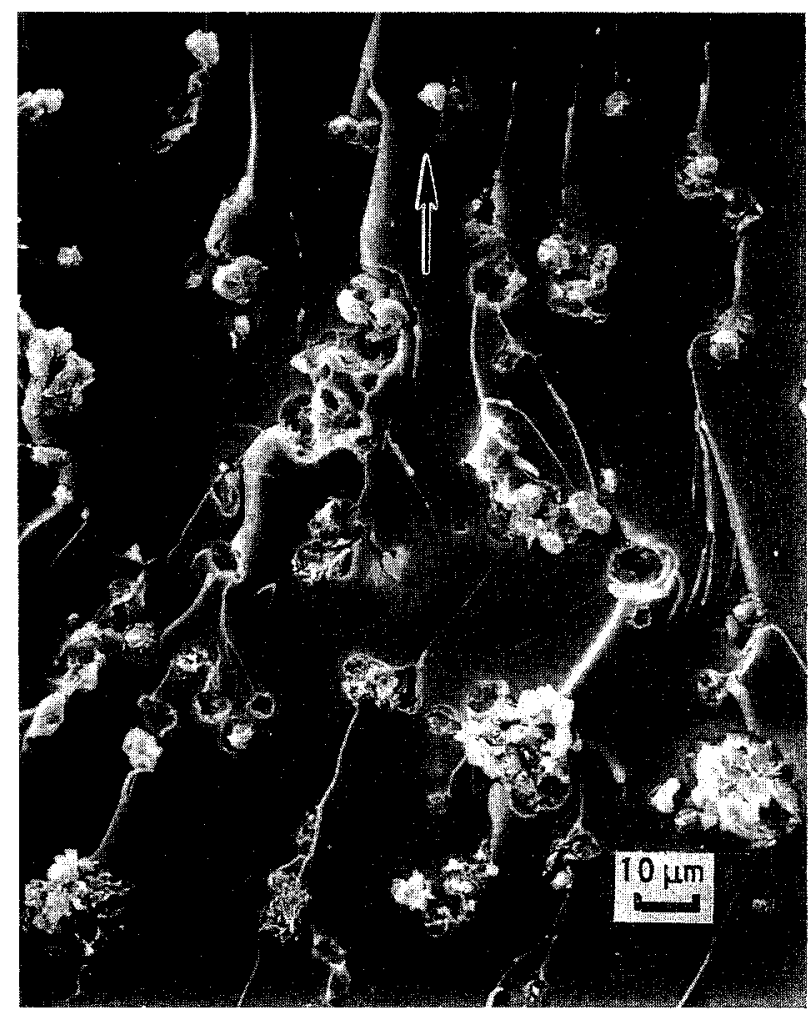

Figure 6 Scanning electron micrograph of the fracture surface of PBT-epoxy blend made by Process 1 (10 wt \%, $15 \mu \mathrm{m}$ PBT). Arrow indicates the crack propagation direction.

behaviour of the PBT particles. This is indicated by the fibrous texture present on the PBT fracture surfaces.

The general fracture surface morphology occurring with PBT-epoxy blends made by Process 2 is shown in Fig. 8. As can be seen, the PBT phase after mixing and precipitation was spherical in shape with a diameter $8-10 \mu \mathrm{m}$. The size remained nearly the same irrespective of the amount of PBT or the initial PBT particle size before mixing. Again, there occurred behind nearly every PBT particle one or more crack bifurcation lines, but the size of the welts is diminished from the size of those occurring in materials made by Process 1. As can be seen in Fig. 9, the amount of PBT 

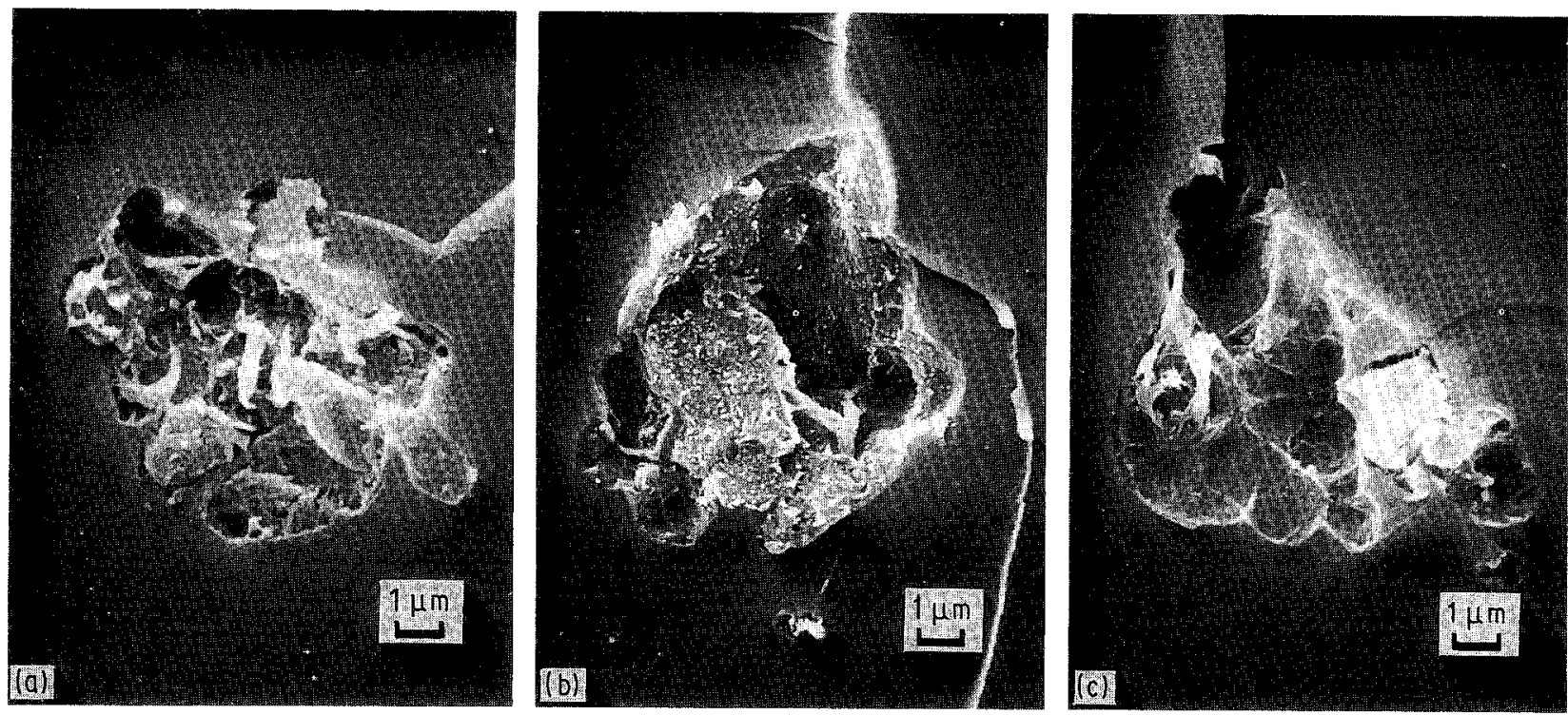

Figure 7 Scanning electron micrographs of the fracture surfaces of PBT-epoxy blends made by Process 1 with different PBT compositions: (a) $5 \mathrm{wt} \%$, (b) (10) wt $\%$, (c) $20 \mathrm{wt} \%$.

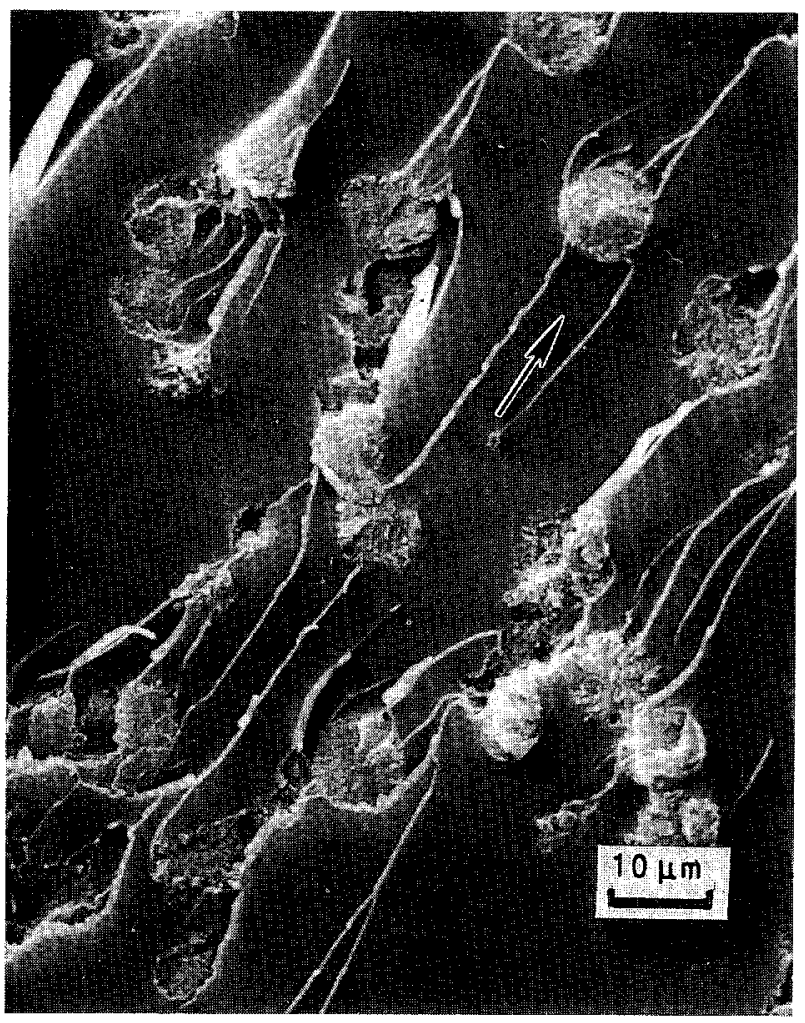

Figure 8 Scanning electron micrograph of the fracture surface of PBT-epoxy blend made by Process 2 (10 wt \% PBT). Arrow indicates the crack propagation direction.

in the blend affected the fracture behaviour. A rotation of the BLT about the particles occurred for the 5 and $10 \mathrm{wt} \%$ PBT blend, but not for the $20 \mathrm{wt} \%$ PBT blends. Also, the number of bifurcation lines increased but their width decreased as the concentration of PBT increased. In addition, though not especially evident in Fig. 9, the fracture surface of the PBT tended to become smoother with increasing PBT composition.

The general fracture surface morphology occurring with PBT-epoxy blends made by Process 3 is shown in Fig. 10, and details of the fracture surface for 5, 10, and $20 \mathrm{wt} \%$ PBT are shown in Fig. 11. The PBT phase after mixing and precipitation was spherical in shape, but the size depended on the precipitation/crystallization temperature, which increased with the amount of PBT. The higher the temperature, the larger the size. The average diameters of the PBT particles in the 5, 10, and $20 \mathrm{wt} \%$ PBT-epoxy blend were about 8,25 , and $45 \mu \mathrm{m}$, respectively. The bifurcation lines, when present, were extremely thin, and there is little indication of ductile fracture of the PBT, even with the $5 \mathrm{wt} \%$ PBT blend, where the fracture energy was slightly higher. The PBT fracture surface was nearly flat especially with $20 \mathrm{wt} \%$ PBT.

Micrographs of thin sections, whose planes were perpendicular to the fracture surface and parallel with the direction of crack propagation, are shown in Figs 12 and 13 for $10 \mathrm{wt} \%$ PBT-epoxy blends made by Processes 1 and 3, respectively. The profile of the fracture surface of the PBT-epoxy blend made by Process 1 is very rough; the blend made by Process 3 is relatively smooth. These differences are consistent with the respective fracture energies measured for these two specimens. The PBT phase in the blend made by Process 3 is seen to consist of large spherulites; those made by Process 1 appear to be cohering agglomerates of smaller particles. Because of the absence of well-developed Maltese crosses with crossed polarizers, the spherulites from Process 3, though large, seem imperfect. Also, the crystals in the spherulites seem coarse.

An effect of preparation was also seen on the cavitation zone size in PBT-CTBN rubber-epoxy blends. The effect of PBT on the zone size in PBT-CTBN rubber-epoxy blends when made by Processes 1 is described in Fig. 4. A micrograph of a blend made by Process 3 is shown in Fig. 14. In contrast to the reduction in zone size by the PBT when the blend was made by Process 1, the cavitation zone size remained the same as that of the rubber-epoxy blend without PBT when the PBT-CTBN rubber-epoxy blend was made by Process 3 . 

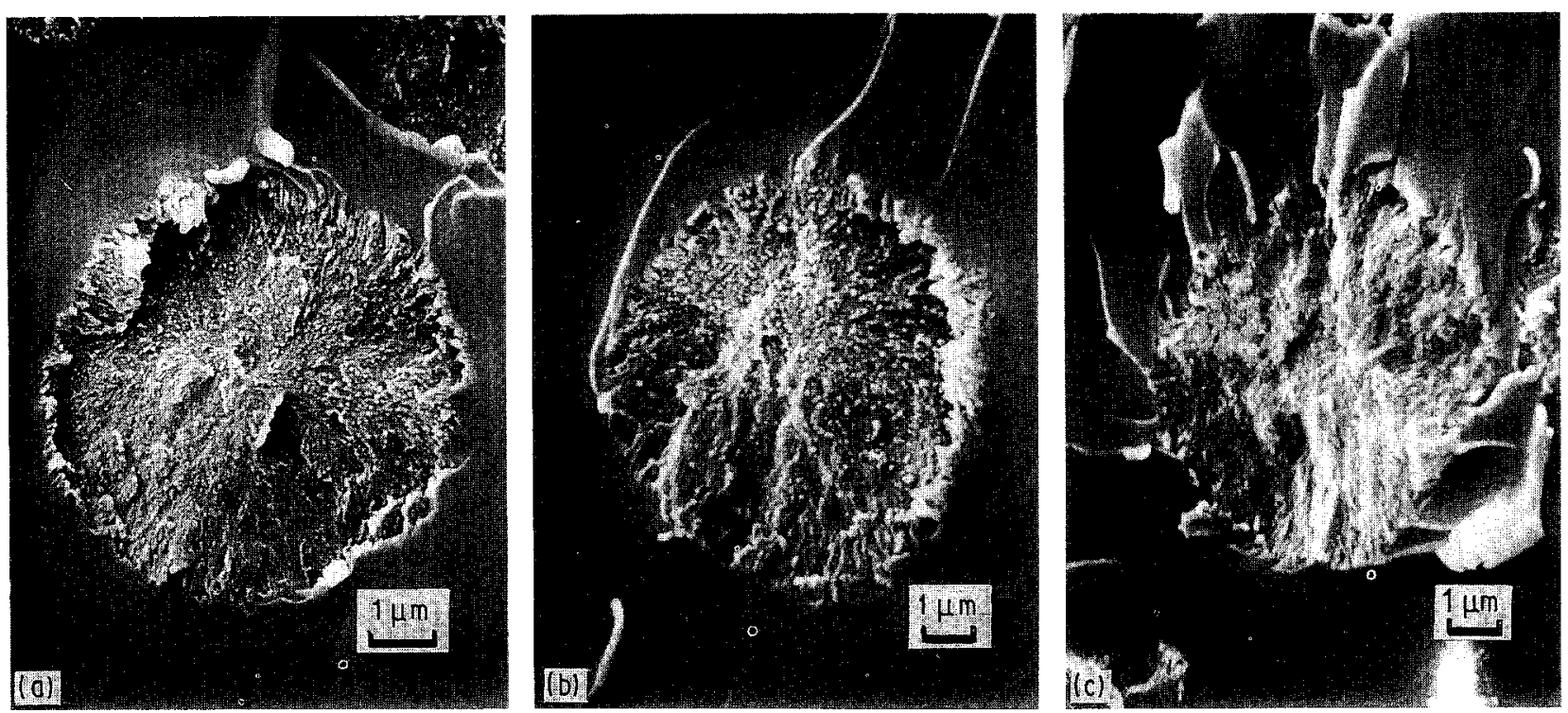

Figure 9 Scanning electron micrographs of the fracture surfaces of PBT-epoxy blends made by Process 2 with different PBT compositions: (a) 5 wt $\%$, (b) $10 \mathrm{wt} \%$, (c) $20 \mathrm{wt} \%$

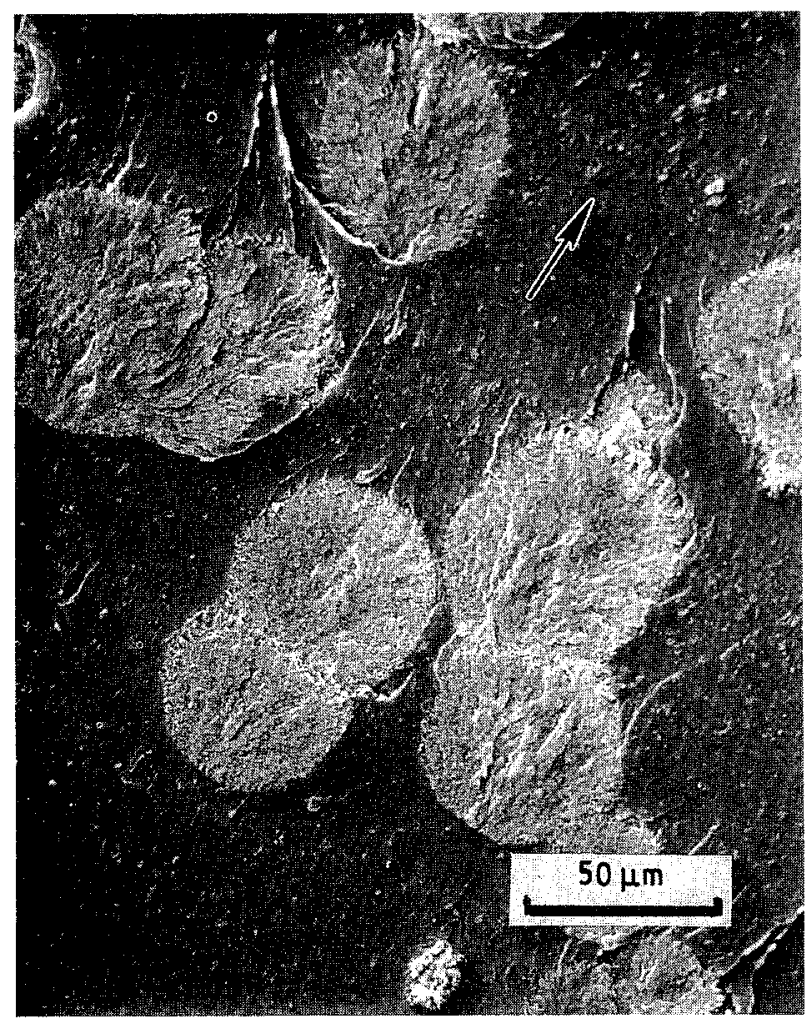

Figure 10 Scanning electron micrograph of fracture surface of PBT-epoxy blend made by Process 3 (20 wt \%, PBT). Arrow indicates the crack propagation direction.

\section{Discussion}

The considerable increase in toughness of the PBT-epoxy blend over that of the other epoxy blends reveals the possibility of a new toughening mechanism, namely, that arising from a phase transformation of the PBT in front of the crack tip. As with zirconia, used to toughen ceramics, PBT exhibits a stress-induced phase transformation with volume expansion. The normal $\alpha$-crystal of PBT can transform to a more extended $\beta$-crystal under stresses along the chain axis. The transformation is thought to arise from a change in the butylene chain conformation from a helix to planar zigzag (from TGTG to TTTT) [27-34]. The densities of the $\alpha$ - and $\beta$-structures are reported to be 1.40 and $1.28 \mathrm{Mg} \mathrm{m}^{-3}$, respectively, so that a deformation-induced volume increase of about $9 \%$ is possible. Even under tensile strains less of than $2 \%$, the transformation from the $\alpha$ - to $\beta$-structures occurs with volume expansion. There occurs a reverse transformation from the $\beta$ - to $\alpha$-phase when the applied stress is released, however, so that direct proof for a phase transformation of PBT during fracture has not been possible.

The mode of action of the PBT in toughening the matrix can be viewed in two ways. First, in analogy with the toughening of ceramics by zirconia, the expansion of the PBT particles can be expected to mute the triaxial tensile stress field extending in front of the crack tip. Thus, a larger applied stress is required to drive a crack through a PBT-polymer matrix blend than through the polymer matrix without the PBT. Second, the expansion of the PBT particles absorbs energy from the stress field, and this contributes to the fracture energy. This stress required to transform the $\alpha$ - to the $\beta$-structure is about $70 \mathrm{MPa}$ and entails $9 \%$ $-10 \%$ strain [31]. Thus, the energy involved is about $7 \mathrm{MJ} \mathrm{m}^{-3}$. The zone within which the tensile stress exceeds $70 \mathrm{MPa}$ should be larger than that where rubber particles cavitate, which is seen in Fig. 3 to be $25 \mu \mathrm{m}$ on each side of the fracture plane. Because the deformation of PBT particles is visible at distances up to $125 \mu \mathrm{m}$ away from the fracture plane (see Fig. 11 in [10]), the PBT-transformation zone size could approach $0.25 \mathrm{~mm}$, including both sides of the crack. A zone of this size, within which the PBT yield stress of $70 \mathrm{MPa}$ could be reached or exceeded, is also supported by a stress analysis around the crack tip. The energy absorbed by the $\alpha$ - to $\beta$-phase transformation of the PBT particles in 5, 10, and 20 vol \% PBT blends could be approximately 90,175 , and $350 \mathrm{~J} \mathrm{~m}^{-2}$. The contribution of these to the fracture energy is uncertain, but if these blends behave like other materials, 

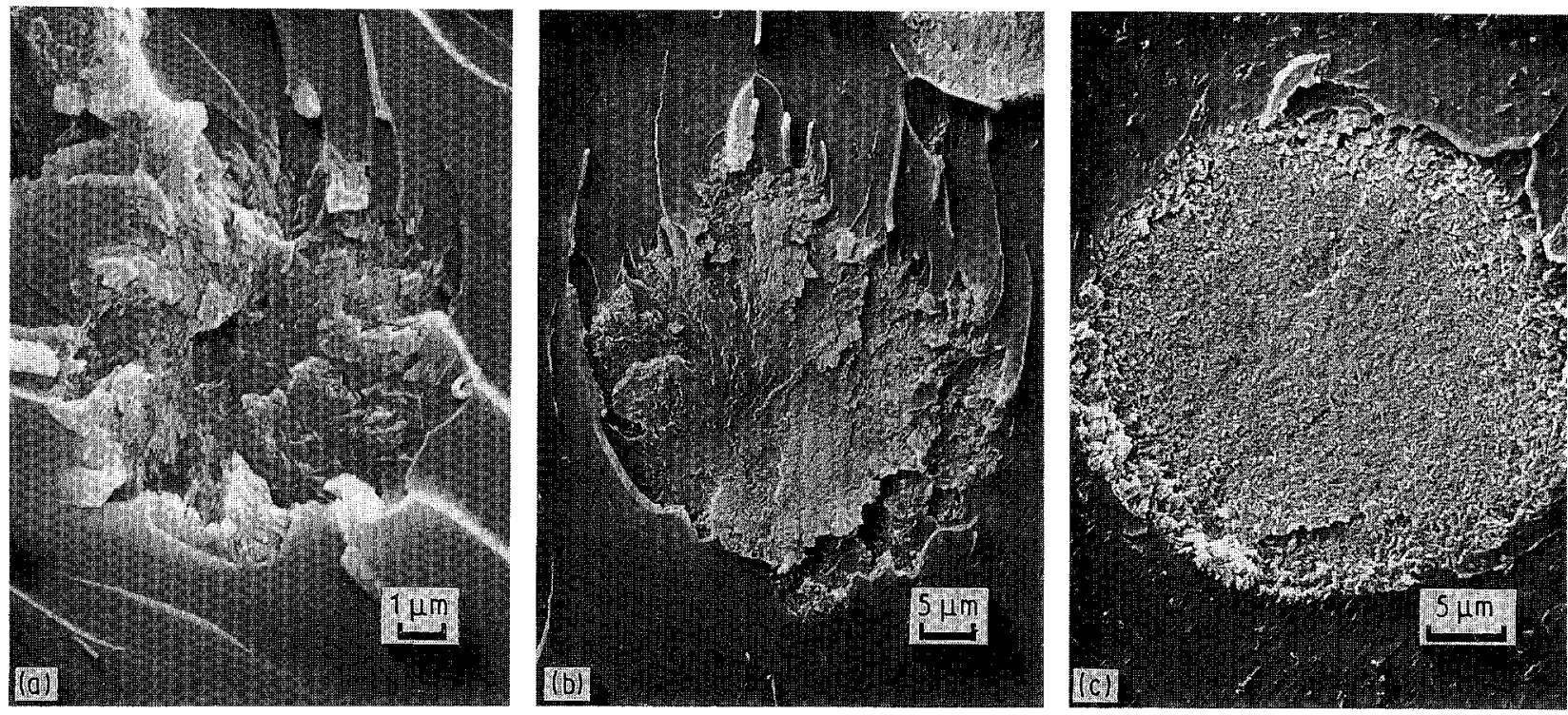

Figure 11 Scanning electron micrographs of the fracture surfaces of PBT-epoxy blends made by Process 3 with different PBT compositions: (a) $5 \mathrm{wt} \%$, (b) $10 \mathrm{wt} \%$, (c) $20 \mathrm{wt} \%$.
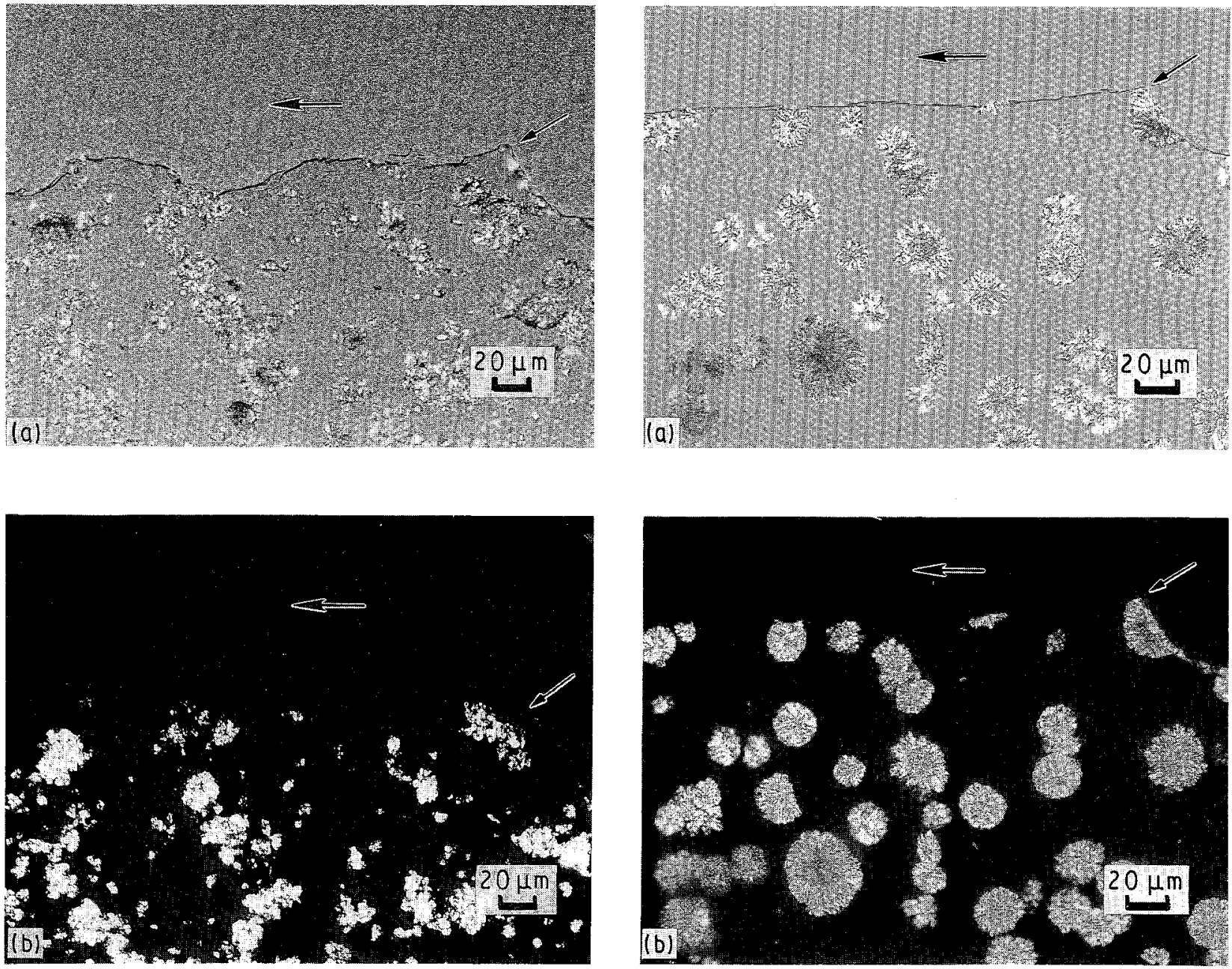

Figure 12 Optical micrographs of thin section perpendicular to the fracture surface of PBT-epoxy blend made by process $1:$ (a) $45^{\circ}$ to polar, (b) $90^{\circ}$ to polar. Large and small arrows indicate the crack propagation direction and blunt notch tip, respectively.

the contribution would be several times these values. (The discrepancy between actual energy-absorbing processes and their contributions to the fracture energy was first found by Griffith upon correcting a

Figure 13 Optical micrographs of thin section perpendicular to the fracture surface of PBT-epoxy blend made by process 3 : (a) $45^{\circ}$ to polar, (b) $90^{\circ}$ to polar. Large and small arrows indicate the crack propagation direction and blunt notch tip, respectively.

mistake in his analysis $[35,36]$. The measured fracture energy, instead of being equal to the total surface energy of newly created crack, was found to be three times the surface energy. This discrepancy is often 


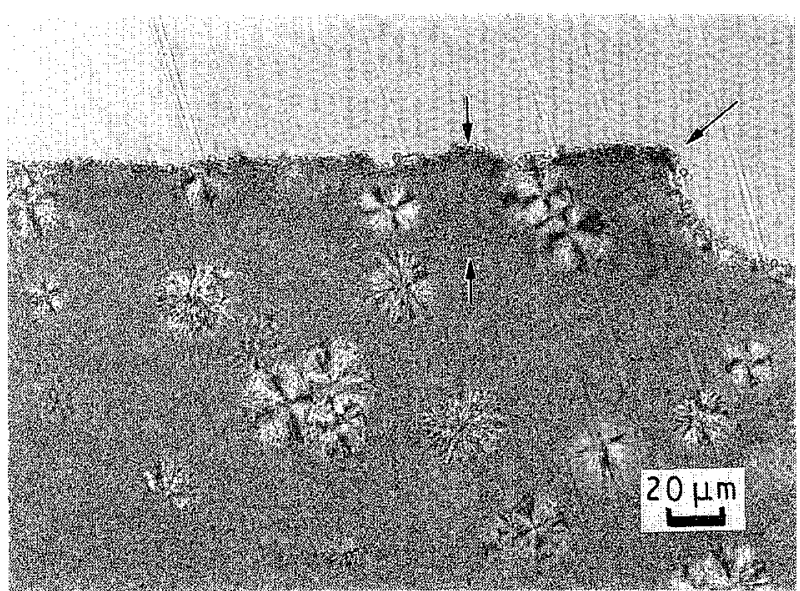

Figure 14 Optical micrograph of a thin section perpendicular to the fracture surface of a $10 \mathrm{wt} \% \mathrm{PBT}, 10 \mathrm{wt} \%$ rubber-epoxy blend made by Process 3. The single arrow indicates the point of crack initiation at the root of a notch; propagation was to the left. The pair of arrows indicate the width of the cavitation zone.

rationalized today as resulting from the neglect of inelastic strain. But after Irwin and Orowan had generalized the Griffith fracture concept to include plastic work as well as surface energy, Felbeck and Orowan found that the plastic work of metals suggested by the fracture energy remained two to five times greater than the plastic work indicated by X-ray analysis of the fracture surfaces [37]. Andrews [38], for example, has pointed out the difficulty of calculating the time and temperature-independent fracture energy (the "intrinsic fracture energy") of plastics such as plasticized poly(vinyl chloride), polyethylene, and especially polycarbonate. And we have found the fracture energy of a series of epoxies to be about five times greater than that expected microscopically [39].

\subsection{Cavitation zone size}

The suppression of the cavitation of rubber in the presence of the PBT in PBT-CTBN rubber-epoxy blends strongly suggests the phase transformation of the PBT ahead of the crack tip. As seen in Fig. 4, the cavitation zone size in these blends made by Process 1 continuously decreased with increasing PBT and completely disappeared at $17 \mathrm{wt} \%$. When PBT transforms ahead of the crack tip, because of the volume expansion accompanying the phase transformation, the transformed PBT phases act like pressurized cavities. To the extent that this mechanism is operating, it superimposes a compressive stress field on the triaxial tensile component at the crack tip. As a result, the cavitation of the rubber phase is largely suppressed. Thus, the greater the PBT composition, the greater the amount of phase transformation, and the smaller the amount of rubber cavitation.

\subsection{Selective suppression of toughening Mechanisms}

In addition to phase transformation toughening, the following four toughening mechanisms have been identified for PBT-epoxy blends made by Process 1
[10]: (1) primary crack bridging, (2) crack bifurcation, (3) secondary crack bridging, and (4) ductile fracture of the particles.

Primary crack bridging is discernable from the basic longitudinal texture (BLT). The rotation of the BLT around the PBT particles indicates that the particles are not fractured or pulled away from the matrix immediately upon the crack reaching them. In holding the crack together, the unfractured particles limit crack opening and reduce the stress at the crack front. Primary crack bridging depends on the strength of the particles and the adhesion of the particles to the matrix.

Crack bifurcation has been induced at nearly every PBT particle in the blend made by Process 1 (Figs 6 and 7). The bifurcation is indicated by the tail-like bifurcation line behind each particle. The bifurcation line is actually a step and, for about one-half of the steps, an associated "welt" [40]. The steps and welts or bifurcation lines in Figs. 6 and 7 result from the following process $[41,42]$. The crack divides when it reaches each particle, and the paths of the two parts of the crack, as they travel around the two sides of the particle, tend to wander independently of one another or become altered asymmetrically. As a result, when they come together behind the particle, they are at different elevations. In rejoining, the pair of cracks carve out a pair of steps and a single welt. The welt, with a diameter that is roughly equal to the difference in elevation between the two parts of the crack, is usually partially attached to one of the two steps. The partially attached welts are a prominent feature in scanning electron micrographs of fracture surfaces because they usually acquire electric charge faster than it is dissipated and glow white.

Secondary crack bridging is associated with crack bifurcation. It occurs by means of the welt and contributes more to the fracture energy than does the creation of extra crack area during the bifurcation. The welt, being attached to both fracture surfaces, is a ligament that tends to hold the surfaces together. It is stretched and fractured as the two separate. The greater the asymmetry in the two crack paths around the particles, the greater will be the difference in elevation of the crack when they rejoin, and the greater will be the size of the welt. The greater the size of the welt, the greater will be the bridging effect. Crack-path alteration depends on the volume fraction, size and spacing of the particles, the particle-matrix interfacial strength, and the asymmetry of particle deformation.

Ductile fracture of the PBT particles can absorb a significant amount of energy if the behaviour of these small particles is similar to that of bulk PBT. Only particles at the fracture surface are involved, however. With $15 \mu \mathrm{m}$ diameter particles undergoing $100 \%$ strain at a yield stress of $70 \mathrm{MPa}$, this mechanism probably absorbs energy of the order of $100 \mathrm{~J} \mathrm{~m}^{-2}$ with $10 \mathrm{wt} \%$ PBT. Again, the contribution to the fracture energy is expected to be several times this.

These four mechanisms and phase transformation toughening contribute differently to the toughening of the PBT-epoxy blends made by Processes 2 and 3 than they do to the toughening of the blends made by 
Process 1; and for the blends made by Process 2 , the difference in behaviour increases with increasing PBT content. Thus, a comparison of Figs $7 \mathrm{a}$ and $9 \mathrm{a}$ shows that the 5 wt \% PBT blend made by Process 2 differs from that made by Process 1 largely in the muting of the ductile behaviour, but the primary crack bridging, the crack bifurcation, and the secondary crack bridging are nearly the same, as would be the phase transformation toughening. A comparison of Figs $7 \mathrm{~b}$ and $9 b$ shows that the 10 wt \% PBT blend made by Process 2 differs from that made by Process 1 more significantly. Besides the general loss of the ductile fracture of the PBT particles, the crack bifurcation and secondary crack bridging are also suppressed, leaving some primary crack bridging and the phase transformation toughening. For the $20 \mathrm{wt} \%$ PBT blend, all of the toughening mechanisms except for phase transformation toughening appear to be suppressed. Phase transformation toughening, if present, is expected not to be suppressed for this blend. Except for the periphery of the particles, which underwent dissolution in the epoxy and recrystallization during processing, the remaining part of the particle should be just the same as the PBT particles in the blends made by Process 1 . But the fact that the fracture energy of this blend $\left(740 \mathrm{~J} \mathrm{~m}^{-2}\right)$ is still much greater than that of the base resin $\left(190 \mathrm{~J} \mathrm{~m}^{-2}\right)$ supports the suggestion of phase transformation toughening in this system.

An examination of the fracture surface morphology of the blends made by Process 3 (Fig. 11) indicates that all of the toughening mechanisms that leave remnants of their presence on the fracture surfaces were suppressed, especially for the higher PBT-content blends. A possible exception is the blend with 5 wt $\%$ PBT (Fig. 11a), where the PBT fracture surface is complex, but not ductile, and there is some minor crack bifurcation and secondary crack bridging. The inability of the PBT in blends with CTBN rubber to suppress the cavitation zone size (Fig. 14) indicates that even phase transformation toughening has been suppressed. These deductions are consistent with the measured fracture energies of these PBT-epoxy blends, which were little different from that of the base resin, as noted in Fig. 5.

The difference in behaviour between the PBT-epoxy blends made by Process 1 and those made by Processes 2 and 3 arises from the dissolution of at least some of the PBT in and recrystallization from the epoxy in the latter two processes. When mixed at temperatures above $220^{\circ} \mathrm{C}$, PBT dissolves in the epoxy to form a homogeneous solution. Then, when the solution is cooled, the PBT recrystallizes as spherulites. Uniformly space-filling spherulites usually consist of crystalline substructures that radiate from a centre, branch at small angles, and are surrounded by space-filling amorphous material. For the recrystallization of PBT, the crystalline phase inside the spherulites is surrounded by a mixture of epoxy and PBT molecules that have not crystallized. According to Keith and Padden, the coarseness of the spherulitic texture is related to the concentration of impurity (the epoxy) and is determined by $\delta-D / G$, where $D$ is the diffusion coefficient of the impurity and $G$ is the radial growth rate of the spherulites $[43,44]$. Higher $D / G$ ratios correspond to coarser textures. With increasing crystallization temperature, which occur with increasing PBT composition, the diffusivity of the epoxy increases and the crystal growth rate decreases. As a result, the $D / G$ ratio increases and the spherulites become coarser.

Agitation during mixing also affects the coarseness of the spherulites. Without mechanical stirring, PBT is slow to mix with the epoxy because of its high viscosity, and PBT-rich regions usually remain in the mixture. This was the result in Process 2. With an adequately high degree of agitation during mixing, however, the local PBT-rich regions can be eliminated and a uniform concentration attained. This occurred in Process 3 . For Process 2 , the $D / G$ ratio is high only in the space around the PBT-rich regions, and the PBT here crystallizes as a coarse spherulitic coat on melt-crystallized-like cores. For Process 3, the $D / G$ ratio is high throughout, yielding the coarse spherulites observed (Figs 13 and 14).

As spherulites become coarser, the amount of epoxy containing dissolved PBT increases inside the spherulite, and this tends to isolate PBT crystalline segments. The degree of cure of the epoxy remaining within the PBT spherulite can affect the fracture energy and other properties. If the epoxy within the PBT spherulite is not cured, the spherulites cannot support the applied load and would act like cavities. But for all of the PBT-epoxy blends made by Processes 2 and 3, the tensile modulus and yield strength were found to have remained undiminished from those of the cured epoxy [45], which indicates that the epoxy located in PBT spherulites is sufficiently cured.

The phase transformation toughening mechanism, if it is operative, is expected to be affected by the isolation of the PBT crystalline phase. For the PBT crystals to transform, the crystals should be oriented with the axis of the applied load along the PBT chain axis. The PBT crystals have all orientations in a spherulite, however, and the transformation is less likely when the chain axis is tilted away from the axis of the applied tensile stress. To obtain phase transformation of whole PBT particles, the axes of these crystals must rotate to align the PBT chain axis with the direction of the applied stress. When the PBT crystals are isolated and surrounded after curing by a rigid mixture of PBT and epoxy, however, the rotation is restricted. As a result, the amount of the phase transformation is expected to decrease with increasing degree of isolation of the PBT crystals. This was seen to have occurred with the PBT-epoxy blends made by Process 3 and probably occurred in the periphery of the PBT particles in the blends made by Process 2 .

\section{Conclusions}

The greater toughness of PBT-epoxy blends than that of other thermoplastic-epoxy blends, such as nylon 6-epoxy or PVDF-epoxy blends, is attributed to phase transformation toughening. Phase transformation toughening can be viewed as either the 
muting of the triaxial tensile stress field extending in front of the crack tip, thus requiring a larger applied stress to drive a crack through the blend, or as the absorption of energy from the stress field.

Phase transformation toughening operates in the PBT-thermoset blends in conjunction with other mechanisms that include (1) primary crack bridging, (2) crack bifurcation and crack path altering, (3) formation of steps and welts and secondary crack bridging, and (4) ductile fracture of the particles. The observations that support phase transformation toughening in PBT-epoxy blends are (1) the suppression of the cavitation of rubber particles in PBT-CTBN rubber-epoxy blends, (2) the selective suppression of the toughening mechanisms other than phase transformation toughening, which left a significant residual toughness enhancement over that of the epoxy alone, and (3) the suppression of all toughening mechanisms including phase transformation toughening, by preventing the PBT from undergoing significant transformation.

Poly(butylene terephthalate) particles appear to be especially effective for toughening thermosets like the epoxy used in this study that are not significantly toughened by rubber. These are thermosets that typically have high glass transition temperatures and show little ductility under plane stress conditions; i.e. the shear lips that form where the crack intersects a free surface are insignificant.

\section{Acknowledgements}

We wish to acknowledge the useful discussions with our colleagues, Professors I-Wei Chen and Albert Yee. This work was supported by the National Science Foundation through a Materials Research Group grant, DMR-8708405.

\section{References}

1. J. N. SUlTAN, R.C. LAIBLE and F. J. McGARRY, J. Appl. Polym. Sci. 6 (1971) 127.

2. A. J. KINLOCH, S. J. SHAW, D. A. TOD and D. L. HUNSTON, Polymer 24 (1983) 1341.

3. A. J. KINLOCH, S. J. SHAW and D. L. HUNSTON, ibid. 24 (1983) 1355.

4. R. A. PEARSON and A. F. YEE, J. Mater. Sci. 21 (1986) 2475.

5. A. F. YEE and R. A. PEARSON, ibid. 21 (1986) 2462.

6. A. J. KINLOCH and D. L. HUNSTON, J. Mater. Sci. Lett. 6 (1987) 137.

7. A. F. YEE and R. A. PEAR SON, J. Mater. Sci. 24 (1989) 2571.

8. J. K. KIM and R. E. ROBERTSON, ibid. in press.

9. N. Claussen, J. Amer. Ceram. Soc. 59 (1976) 49.

10. D. L. PORTER and A. H. HEUER, ibid. 60 (1977) 183.
11. A. G. EVANS and A. H. HEUER, ibid. 63 (1980) 241

12. R. M. McMEEKING and A. G. EVANS, ibid. 65 (1982) 242.

13. I-W. CHEN and P. E. REYES-MOREL, ibid. 69 (1986) 181.

14. L. R. F. ROSS and M. V. SWAIN, ibid. 69 (1986) 203.

15. J. A. KIES and B. J. CLARK, in "Proceedings of the Second International Conference on Fracture", Brighton 1969, edited by P. L. Pratt (Chapman and Hall, London, 1969) p. 83.

16. A. G. EVANS and S. M. WIEDERHORN, J. Mater. Sci. 9 (1974) 270.

17. G. G. TRAnTinA, J. Amer. Ceram, Soc. 60 (1977) 7.

18. A. G, EVANS, L. R, RUSSEL, and D. W. RICHARDSON, Metall. Trans. A. 6A (1975) 707.

19. R. K. GOVIlA, J. Amer. Ceram. Soc. 63 (1980) 319.

20. P. W. R. BEAUMONT and R. J. YOUNG, J. Mater. Sci. 10 (1973) 1334

21. R. J. YOUNG and P. W. R. BEAUMONT, ibid. 12 (1977) 684.

22. S. YAMINI and R. J. YOUNG, ibid. 14 (1979) 1609.

23. J. M. SCOTT, G. M. WELLS and D. C. PHILLIPS, ibid. 15 (1980) 1436

24. P. S. LEEVERS and J. G. WILLIAMS, ibid. 22 (1987) 1097

25. W. J. CANTWELL, A. C. ROULIN-MOLONEY and K. H. KAUSCH, J. Mater. Sci. Lett. 7 (1988) 976.

26. A. S. HOLIK, R. P. KAMBOUR, S. Y. HOBBS and D. G FIN K, Microstruct. Sci. 7 (1979) 357.

27. I. M. WARD, M. A. WILDING and H. J. BRODY, J. Polym. Sci. Polym. Phys. Ed. 14 (1976) 41

28. I. M. HALL and M. G. PASS, Polymer 17 (1976) 807.

29. M. YOKOUCHI, Y SAKAKIBARA, Y. CHATANI, H TADOKORO, T. TANAKA and K. YODA, Macromol. 9 (1976) 266.

30. B. STAMBAUGH, J. L. KOENIG and J. B. LANDO, $J$ Polym. Sci. Polym. Phys. Ed. 17 (1979) 1063.

31. K. TASHIRO, Y. NAKAI, M. KOBAYASHI and H TADOKORO, Macromol. 13 (1980) 137

32. I. S. DAVIDSON, A. J. MANUEL and I. M. WARD, Polymer 24 (1983) 30

33. B. C. PERRY, J. L. KOENIG and J. B. LANDO, Macromol. 20 (1987) 422.

34. B. C. PERRY, R. B. GRASSO, J. L. KOENIG and J. B. LANDO, ibid. 22 (1989) 2014.

35. D. J. HAYES, "A General Introduction to Fracture Mechanics", (Mechanical Engineering Publications, London, 1978) pp. $1-8$.

36. A. A. GRiffith, Phil. Trans. R. Soc. A221 (1921) 163.

37. D. K. FELBECK and E. OROWAN, Weld. J. Res. Suppl. 34 (1955) $570 \mathrm{~s}$

38. E. H. ANDREWS, Makromol. Chem. Suppl. 2 (1979) 189.

39. J. S. COVAVISAR UCH and R. E. ROBERTSON, J. Mater. Sci. in press.

40. R. E. ROBERTSON and V. E. MINDroIU, Polym. Engng Sci. 27 (1987) 55.

41. F. W. PRESTON, J. Amer. Ceram. Soc. 14 (1931) 419.

42. R. E. ROBERTSON, V. E. MINDROIU and M.-F CHEUNG, Compos. Sci. Technol. 22 (1985) 197.

43. H. D. KEITH and F. J. PADDEN, J. Appl. Phys. 34 (1963) 2409.

44. Idem, ibid. 35 (1964) 1270.

45. J. K. KIM and R. E. ROBERTSON, in "Toughened Plastics", edited by C. K. Riew and A. J. Kinloch, (American Chemical Society, Washington, D. C.) submitted.

Received 6 February

and accepted 14 June 1991 